\title{
"Chaos" protects health privacy
}

Published at www.cmaj.ca on Nov. 23

$\mathrm{G}$ enetic privacy may be a hotbutton issue but there is an urgent need for better privacy protection for all health records, an Ottawa conference on electronic health information and privacy conference was told Nov. 18.

"There is only one thing that protects privacy today and that is chaos," said Mark Rothstein, director of the Institute for Bioethics, Health Law and Policy at the University of Louisville in Kentucky.

Rothstein explained that his own medical records are scattered through different cities, hospitals and offices of health professionals, some of whom are deceased. "If someone wanted to get their hands on all my medical records, they couldn't. This is not good for continuity of care, but it is wonderful for privacy."

However, the privacy protection afforded by that chaos is threatened because of the advent of interoperable networks of electronic health records, which raises a whole range of issues, he told the audience of about 70 academic, government and private-sector privacy experts at the EHIP [Electronic Health Information and Privacy] 2009 conference.

"Everyone is concerned about security of information, but very few are focusing on the privacy issue," Rothstein said, noting that he defines security as "keeping unauthorized people from getting information."

"We really need to consider what privacy is and how to take steps to protect it," he said, adding that privacy concerns are rampant in this era of biobanks (banks of genetic information), electronic health records, personal health records stored on the Internet, direct-to-consumer genetic tests and websites where people share intimate health information with others with the same medical conditions.

Rothstein, an internationally recognized expert who has written 19 books,

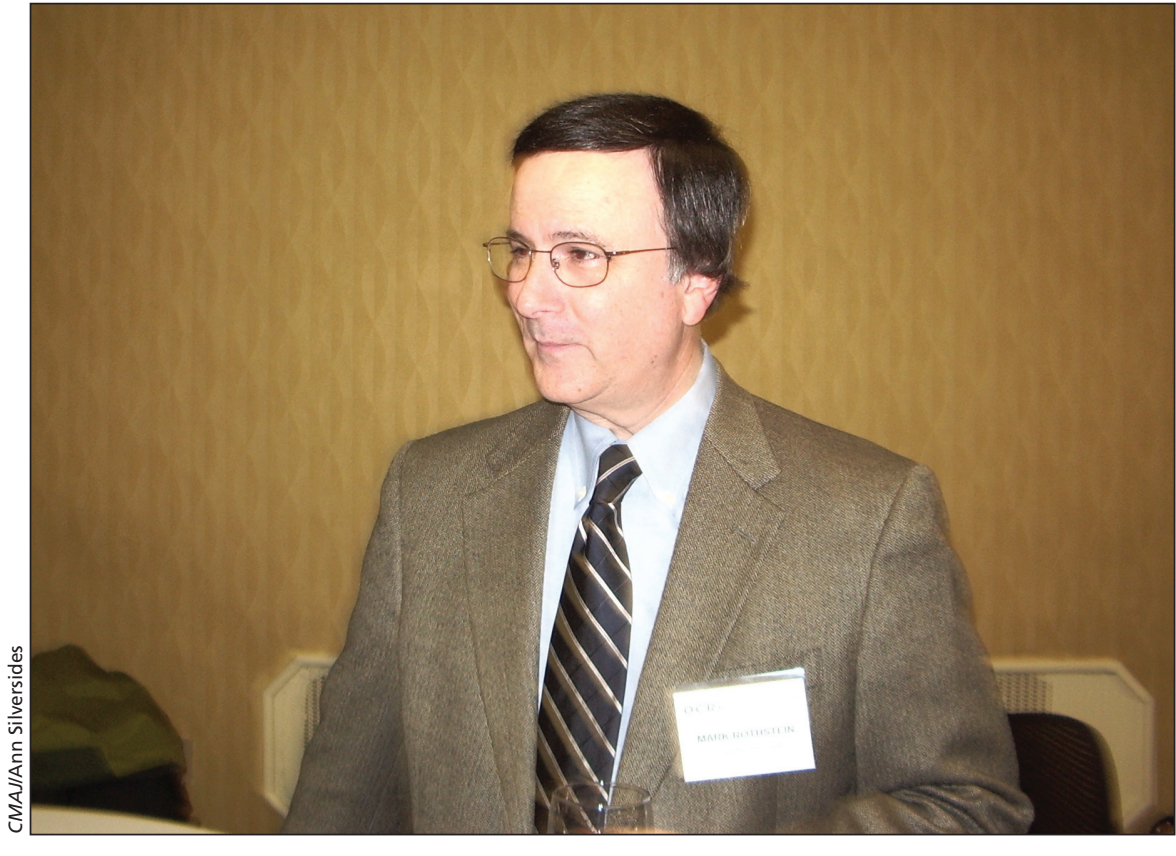

"There is only one thing that protects privacy today and that is chaos," says Mark Rothstein, director of the Institute for Bioethics, Health Law and Policy at the University of Louisville in Kentucky.

argued against the need for a kind of "genetic exceptionalism" when it comes to privacy protection.

It would be "a nightmare" to try to segregate genetic from nongenetic information in health records, he said, because while diseases used to be put into two groups - "genetic disease and everything else" - it is now known that most disorders have a genetic component.

He noted that the "feel good" 2008 Genetic Information Nondiscrimination Act in the United States affords protection for individuals predisposed to disabling genetic conditions. However, the law only protects people who are asymptomatic. Once a person actually develops a genetic condition, such as Huntington disease, health insurers can drop the patient's coverage.

"The law does not protect against discrimination based on the medical condition," he said, adding that a focus on genetic information can be a way to avoid more difficult issues, such as the right to health care.
Meanwhile, Rothstein said, biobanks raise a number of thorny ethical issues, such as ongoing linkage with a person's medical records, consent to future uses of genetic material, the rights of contributors to withdraw their samples and the extent to which researchers are obligated to recontact contributors if particular vulnerabilities are identified in the future.

Freestanding personal health records, such as those available through Google and Microsoft, raise privacy concerns, since monthly fees are charged and vendors can sell data and advertisements, he said.

And the proliferation of unregulated direct-to-consumer genetic testing companies operating on the Internet is troubling because of the lack of clinical validity of tests, variance in interpretation, lack of genetic counselling and the potential for psychosocial harm, he said. "The tests vary so much, as do the risks for the individual, that we may need several different types of regulation.' 
On Nov. 18, deCODE genetics Inc., a publicly traded genetic testing corporation, filed for relief under Chapter 11 of the United States Bankruptcy Code. This development raises issues about the status of the company's assets - the genetic information collected from individuals — and whether bankruptcy trustees would be obligated to sell off these assets, he said.

As for electronic health records, there are a number of ways that information can be better protected, he said.

Some sensitive information, such as mental health or genetic conditions, can be "sequestered" or locked; audit trails could be set up to track those who have had access to records, and there should be "role-based" access restrictions so that, for example, billing clerks have access only to certain information, he said.

As well, individuals using electronic health records should receive training and there should be strict penalties for violations such as snooping, he added.

Finally, Rothstein questioned what information life insurance companies should be legitimately entitled to. "They really only need 10 to 12 fields of information to decide if someone is low- or high-risk." — Ann Silversides, CMAJ

DOII:10.1503/cmaj.109-3115 